\title{
Nueva fase de desarrollo y determinantes de la acción estatal frente a la crisis del neoliberalismo: hacia una visión socioespacial*
}

Sergio Ordóñez**

\section{RESUMEN}

Este trabajo contribuye a la discusión orientada a superar las insuficiencias de la literatura sobre el Estado y su accionar en la reproducción y el desarrollo económico, a la luz de la emergencia de una nueva fase de desarrollo del capitalismo, o capitalismo del conocimiento, y de la actual crisis del neoliberalismo. En polémica con el institucionalismo -en tanto que referente teórico abarcador-, se aportan elementos para avanzar en la integración de las dimensiones política y económica de la teoría del Estado, en torno al concepto gramsciano de Estado ampliado. Con base en ello, se intenta adelantar en la integración de la dimensión espacial a partir de los aportes más avanzados de la corriente espacial-escalar, para finalmente aproximarse a los determinantes actuales de la acción estatal propios del capitalismo del conocimiento, particularmente desde la perspectiva de los países en desarrollo, determinantes que, al mismo tiempo, constituyen lineamientos de acción estatal de salida a la crisis.

Palabras clave: capitalismo del conocimiento, crisis del neoliberalismo, acción estatal, visión socioespacial, países en desarrollo.

Clasificación JEL: P16, O10, B52, B24, R12, O20.

\begin{abstract}
This paper deals with a contribution to the debate about overcoming the insuficiencies of literature on State action on economic reproduction and development, having in sight the emergence of a new capitalist phase of development, or knowledge capitalism, and the contemporary neoliberalism crisis. Debating with institutionalism -as a comprehensive theoretical reference-, it provides theoretical elements in order to move towards the integration of the political and economic dimensions of State theory, within the framework of enlarged State gramscian concept. On that basis, the article attempts to move towards the integration of the spatial dimension considering the background of the spatial-scalar theoretical reference, so as to approach to the contemporary determinants of State action in knowldege capitalism, particularly from the optics of developing countries; which are determinants of State action to overcome the crisis too.
\end{abstract}

Keywords: knowledge capitalism, neoliberalism crisis, State action, socio-spatial vision, developing countries.

JEL classification: P16, O10, B52, B24, R12, O20.

* Fecha de recepción: 27/02/2013. Fecha de aprobación: 23/05/2014.

** Investigador titular de tiempo completo del Instituto de Investigaciones Económicas de la unAM. Correo electrónico: serorgu@gmail.com. 


\section{INTRODUCCIÓN}

La problemática del desarrollo y su relación con la acción del Estado surge con las primeras experiencias de industrialización en América Latina, las cuales constituyen el sustrato de reflexiones retrospectivas con la misma óptica que en el caso del despegue de los primeros países atrasados, es decir, Estados Unidos (EU) y Alemania, así como de otros que les siguieron, como Rusia y Japón. Ello constituye el antecedente de reflexiones más recientes, con una orientación similar, a partir de la experiencia de los países asiáticos.

El planteamiento de esta problemática es de gran actualidad y pertinencia, debido a que la reciente crisis financiero-productiva global y sus secuelas actuales expresan la del neoliberalismo y su espacialidad en el nuevo regionalismo (global), justificados por las aportaciones más recientes de la teoría neoclásica y la literatura "glocalizadora". Esto, a su vez, significa la crisis de la vía de desarrollo predominante en el mundo, basada en el dogma del libre juego de las fuerzas del mercado y en el desmantelamiento y la fragmentación del espacio nacional, y, por tanto, contraria al Estado y su territorialidad, en el marco más general de la emergencia de una nueva fase de desarrollo del capitalismo, para la cual se propone la denominación de "capitalismo del conocimiento", cuya dimensión espacial es la globalización.

Sin embargo, hasta ahora la literatura sobre el desarrollo y el Estado ha adolecido de las siguientes insuficiencias: a) no ha logrado articular la vertiente política de la teoría del Estado con las vertientes económica y espacial sobre la relación de su accionar con el desarrollo; b) no ha dilucidado cuáles son los determinantes de la acción del Estado en la reproducción y el desarrollo neoeconómicos, ni cómo ello se relaciona con las fases de desarrollo del capitalismo, en la medida en que, presumiblemente, cada fase, en tanto que configuración particular de relaciones de producción básicas que se traduce en una dinámica económico-espacial específica, tiene sus propios determinantes del desarrollo, que la diferencian de otras fases, y c) no ha abordado de manera sistemática los temas anteriores en el caso específico de los países en desarrollo, a diferencia de los países desarrollados.

Este trabajo busca contribuir a una discusión que supere las insuficiencias de la literatura sobre el Estado y su accionar en la reproducción y el desarrollo económico, a la luz de la emergencia de la nueva fase de desarrollo del capitalismo y de la actual crisis del neoliberalismo. Para ello, se parte de la constatación de que sólo dos cuerpos teóricos comprensivos proporcionan los funda- 
mentos para una síntesis de las vertientes política y económica de la teoría del Estado, a saber: el institucionalismo y el marxismo gramsciano. Una tercera corriente, más reciente, la espacial-escalar, tiende a integrar las vertientes económica y espacial, dejando de lado, en lo sustancial, la vertiente política. ${ }^{1}$ Por lo anterior, se plantea de inicio un breve repaso de la posición institucionalista, poniendo en claro sus limitaciones generales en cuanto a alcance histórico y las específicas desde la perspectiva de los países en desarrollo.

Posteriormente, se aborda la contribución de Marx y la aportación gramsciana subsiguiente, en torno al concepto de Estado ampliado, en tanto que se trata de un concepto que posibilita la integración de las vertientes política y económica a partir de una concepción del Estado basada en el antagonismo y la conflictividad sociales propios del capitalismo, lo cual será la base para intentar un avance en la integración teórica de la dimensión espacial a partir de los aportes más avanzados de la corriente espacial-escalar. ${ }^{2}$ Por último, y teniendo como trasfondo histórico la emergencia del capitalismo del conocimiento, se realizará una aproximación a los determinantes actuales de la acción estatal que son

\footnotetext{
${ }^{1}$ Autores como R. Jessop (2008, pp. 44-46) conciben al Estado como una relación social con una "selectividad" de clase, que se fundamenta en la idea de Offe (1975, pp. 126) acerca de su exclusión de la producción, y, por tanto, su dependencia del capital para obtener ingresos. Sobre esta base, el Estado capitalista desempeña una serie de funciones derivadas de la necesidad de garantizar la acumulación de capital, entre las cuales sólo una es de carácter político y consiste en "hacer frente al conjunto de repercusiones sociales y políticas producidas por los cambios de forma en que se muestran las contradicciones y dilemas capitalistas, mediadas por y a través de formas específicas de organización política y movilización social" (Jessop, 2008, p. 52). Es decir, estas concepciones no se fundamentan en un entendimiento de la articulación "orgánica" de lo económico con lo político-social, lo que posibilita concebir al Estado no como relación social, sino como condensación de las relaciones políticas - en sentido restringido- y sociales -en sentido ampliado-, en términos de bloque histórico, lo que constituye una de las grandes aportaciones gramscianas a la teoría del Estado, como ha sido estudiado en profundidad por Ordóñez (2010, p. 54) y se desarrollará brevemente más adelante. En lo fundamental, N. Brenner (2004, p. 72) retoma la concepción general del Estado capitalista de Jessop, desarrollando rigurosa y ampliamente su dimensión espacial.

${ }^{2}$ Estos aportes parten de la consideración de que las relaciones sociales tienen dos dimensiones materiales: el espacio y el tiempo. En ese sentido, ambas resultan de un proceso de construcción social y guardan entre sí una relación contradictoria, en la que al mismo tiempo que son complementarias (el espacio está en función del tiempo y viceversa), son excluyentes también (la absolutización del espacio niega al tiempo y viceversa). En esta perspectiva, el espacio es, simultáneamente, una condición dada heredada del pasado, un medio y un resultado de relaciones sociales que en el capitalismo no pueden ser sino relaciones sociales hegemónicas (de dominación). El espacio no es, entonces, un contenedor en donde las relaciones sociales tienen lugar o un mero soporte, ni una "cosa" dada, sino un proceso en constante cambio, concepción que rompe así con el fetichismo del espacio (Brenner, 2004, p. 74).
} 
propios de esta fase de desarrollo, particularmente desde la perspectiva de los países en desarrollo y en el marco de la crisis del neoliberalismo, determinantes que, al mismo tiempo, constituyen lineamientos de acción estatal de salida a la crisis.

\section{LA PROPUESTA INSTITUCIONALISTA DE INTEGRACIÓN DE LAS VERTIENTES POLÍTICA Y ECONÓMICA DE LA TEORÍA DEL ESTADO Y SUS LIMITACIONES}

Desde el punto de vista del institucionalismo, y particularmente de North (1990), las instituciones económicas son organizaciones contractuales que especifican y estructuran los derechos de propiedad, y el conflicto social se presenta en una doble dimensión: 1) entre los agentes que buscan la reducción y costos de transacción "eficientes" y 2) entre aquéllos y los "gobernantes", o el Estado, el cual estructura los derechos de propiedad buscando maximizar su "renta", para lo cual cuenta con la ventaja competitiva del ejercicio de la violencia que le proporciona el derecho de exclusión.

De acuerdo con ese marco, los países avanzados o en desarrollo que han logrado un desenvolvimiento "exitoso", lo habrían hecho porque en el segundo nivel del conflicto social se habrían impuesto los agentes sobre el Estado, conformando un régimen "abierto" de derechos de propiedad que permite el acceso más o menos extendido de la sociedad a las fuentes de riqueza, lo que incrementa la producción. Por el contrario, los países "retardatarios" mantendrían regímenes "cerrados" de derechos de propiedad, resultantes de que en el segundo nivel del conflicto se impone el Estado y los gobernantes sobre los agentes, monopolizando las fuentes de riqueza y excluyendo a grandes capas de la población de su acceso. El pasaje de la segunda situación a la primera tendría lugar por el efecto combinado de una conmoción o "choque de primer orden", que hace inviable la definición prevaleciente hasta el momento de los derechos de propiedad, con un "choque de segundo orden", que implica, como resultado de lo anterior, la formación de una nueva coalición política gobernante que se orienta a una nueva definición "abierta" de los derechos de propiedad, lo que completaría un "cambio de trayectoria" social (Rivera, 2010, p. 78). ${ }^{3}$

${ }^{3}$ La combinación de "choques" es necesaria para "salir de la trampa del atraso", entendida como "un patrón de funcionamiento de la sociedad que tiende a reproducirse por mecanismos institucionales" (Rivera, 2010, p. 78). 
En una aportación posterior, North, Wallis y Weingast (2009, p. 112) agregan que la transición a un régimen "abierto" de derechos de propiedad requiere de la plena competencia tanto económica como política -que se realiza mediante un proceso económico-político de destrucción creativa-, en una dinámica en la cual se produce un momento en que la coalición dominante, por miedo a la rebelión de otras élites, ve más conveniente la apertura de los derechos de propiedad que continuar con el estado de exclusión vigente -convirtiendo los antiguos privilegios en derechos impersonales-. En esta situación, el desarrollo de la competencia impide la subsiguiente manipulación del sistema económico por el sistema político para la obtención de rentas que aseguren el orden político, lo que supone un desarrollo de la sociedad civil y un papel necesariamente más reducido del Estado en el proceso, lo que resulta contrario a la experiencia reciente de los países en desarrollo que han tenido "exito", como ha sido planteado por otra vertiente del institucionalismo respecto al concepto de "Estado desarrollista" para el caso asiático (Block y Evans, 2007, p. 315; Chibber, 2003, p. 29).

Pero el punto de partida de North resulta apologético del Estado capitalista, en la medida en que implica que su función es definir los derechos de propiedad o, en otras palabras, restringir el antagonismo y el conflicto sociales entre las clases y grupos exclusivamente al terreno de la disputa de la propiedad privada en los ámbitos de la competencia económica y política. Por el contrario, aquí se recupera el principio marxista de que el capitalismo, en cualquiera de sus fases de desarrollo, se sustenta en el antagonismo entre capital y trabajo, lo cual implica, por definición, la desposesión de toda propiedad sobre los medios de producción por parte del trabajo u obrero colectivo, por lo que su lucha histórica es por la socialización de esos medios de producción y no la disputa por su propiedad.

En esa medida, la función del Estado no es definir los derechos de propiedad, como sostiene el institucionalismo y en especial North (1990), sino mantener la hegemonía de las clases y grupos dirigentes sobre el conjunto de la sociedad, lo que le posibilita, precisamente, definir esos derechos de propiedad. Por esa razón, se abordan a continuación la contribución de Marx y la aportación gramsciana subsiguiente en torno al concepto de Estado ampliado como marco teórico que permite avanzar en la integración de las vertientes política, económica y espacial de la teoría del Estado, teniendo como su eje explicativo el antagonismo y la conflictividad sociales. 


\section{HACIA UNA VISIÓN SOCIOESPACIAL DEL ESTADO DESDE EL MARXISMO GRAMSCIANO Y LA PERSPECTIVA DE LOS PAÍSES EN DESARROLLO}

\section{Hacia una visión socioespacial del Estado y los determinantes de su accionar}

El punto de partida de la aportación gramsciana al marxismo es la constatación de la doble dimensión histórica del capitalismo, entendido como modo de producción -que es la aportación de Marx (1999)- y como sucesión de fases históricas de desarrollo, o sea, como unidades cambiantes entre economía, política, ideología, cultura e instituciones, que constituyen fases históricas de desarrollo en el seno del modo de producción. ${ }^{4}$ En esta perspectiva, el problema que se plantea Gramsci (1975) es cómo explicar, partiendo del marco teórico marxista, el surgimiento y la decadencia de fases históricas de desarrollo del capitalismo, sin que las crisis en la historia que median este pasaje deriven en un proceso de revolución social que conduzca al socialismo científico previsto por Marx. ${ }^{5}$ Para ello, formula una serie de conceptos de mediación metodológica, articulados en torno al concepto de hegemonía ${ }^{6}$-entendida como la capacidad de una clase social de articular sus intereses con los de otras clases y grupos en un proyecto histórico

\footnotetext{
${ }^{4}$ Marx se refiere a las fases o estadios de desarrollo del capitalismo cuando estudia la cooperación, la manufactura y la gran industria, constituyendo esta última la base material del modo de producción específicamente capitalista (Marx, 1999, pp. 451-480). Sobre esta base, autores como Lenin (1977) y Hilferding (1963) estudian el capitalismo monopolista como "fase" del capitalismo dentro del marxismo "clásico", y en esa línea de continuidad Mandel se refiere al "capitalismo tardío" como "fase" o "etapa" del capitalismo. En otra perspectiva, el regulacionismo concibe la articulación entre régimen de acumulación y modo de regulación como fundamento de modalidades históricas del capitalismo. Fuera del marxismo (aunque con herencia de él), los neoschumpeterianos, y particularmente Carlota Pérez (2004), se refieren a las revoluciones tecnológicas como el fundamento de paradigmas tecnoeconómicos que se articulan con sistemas socioinstitucionales para constituir "épocas". La concepción de la que aquí se parte trata de articular la teoría de los ciclos largos con la de las unidades orgánicas del capitalismo como construcción socioespacial, de Gramsci, pero incorporando la dimensión espacial de las relaciones sociales aludida en la nota 2.

${ }^{5} \mathrm{El}$ punto de partida de toda la construcción teórica gramsciana es la doble afirmación de Marx en el prologo a la Contribución a la crítica de la economía política: "Una sociedad no desaparece nunca antes de que sean desarrolladas todas las fuerzas productivas que pueda contener, y las relaciones de producción nuevas y superiores no se sustituyen jamás en ella antes de que las condiciones materiales de existencia de esas relaciones hayan sido incubadas en el seno mismo de la vieja sociedad" (Marx, 1833, p. 13).

${ }^{6}$ Conceptos como bloque histórico, revolución pasiva, intelectuales, Estado ampliado, sistema de hegemonía de estados, etcétera.
} 
dirigido por ella y que se realiza cuando se vuelve dominante- en un doble sentido: 1) entre la doble dimensión histórica del capitalismo mencionada y 2), en esa perspectiva, entre la estructura económica y las clases y grupos sociales y su posibilidades de acción.

En esa doble dimensión histórica del capitalismo es necesario considerar la contradicción espacial inmanente a éste, en términos de la doble tendencia a la desterritorialización/reterritorialización que se expresa en la tendencia a la igualación de la inversión de capital a través del espacio y la contratendencia a diferenciar esa inversión con el fin de explotar las condiciones específicas del lugar, el territorio y la escala (Smith, 1990, citado por Brenner, 2004, p. 96). ${ }^{7}$ En consecuencia, cada fase de desarrollo implica patrones históricamente específicos de desarrollo geográfico desigual en donde, y por medio de los cuales, se articula la relación contradictoria entre igualación y diferenciación espacial. Estos patrones de polarización socioespacial se cristalizan "horizontalmente" entre diferentes tipos de lugares y territorios, y "verticalmente" entre escalas geográficas divergentes que se extienden desde lo local, regional y nacional a lo continental y global (Brenner, 2004, pp. 102-103).

Desde el punto de vista histórico, las fases de desarrollo suponen la conformación de un nuevo bloque histórico o nueva unidad entre estructura y trama socioespacial e institucional (superestructura) que consiste en la conformación, histórica y espacial, de un conjunto repetitivo de praxis sociales e individuales en torno a un proyecto histórico común que implica acuerdos, alianzas y compromisos entre las clases y grupos que configuran y reconfiguran un espacio nacional. ${ }^{8}$ A la conformación del nuevo bloque histórico corresponde el Estado en un sentido amplio o Estado ampliado, el cual consiste en el conjunto de actividades teórico-prácticas mediante las cuales las clases y los grupos dominantes no sólo justifican y mantienen su dominación, sino que, además, logran el consenso activo de las clases y grupos subalternos, lo que resulta en la configuración del mismo espacio nacional. ${ }^{9}$

\footnotetext{
${ }^{7}$ Marx (1999) se refiere a la tendencia a la desterritorialización expansiva del capital como una dinámica de anulación del espacio por el tiempo. Por su parte, Harvey se refiere a esa tendencia espacio-temporal implícita en la relación (social) del capital como procesos de "compresión espacio-temporal" (Brenner, 2004, p. 91).

${ }^{8}$ Tales acuerdos, alianzas y compromisos tienen lugar espacialmente en el doble sentido "horizontal" y "vertical" antes referido, que determina una jerarquización de las escalas, y, por tanto, una configuración multiescalar del espacio nacional.

${ }^{9}$ En términos de Gramsci, una nueva fase del capitalismo no puede constituirse sin la formación de un nuevo bloque histórico, es decir, sin una nueva hegemonía del grupo social que dirige el
} 
En consecuencia, el de Estado ampliado puede ser visto como el reflejo invertido del concepto de bloque histórico: en tanto éste se refiere al complejo de acuerdos, alianzas y compromisos entre el conjunto de clases y grupos sociales que dan como resultado la configuración y reconfiguración de un espacio nacional en torno a un proyecto histórico, aquél lo hace al complejo de praxis de las clases dominantes tendientes a mantener y recrear inclusivamente -en grado variable- su dominación en ese mismo espacio y en términos del mismo proyecto histórico. Lo anterior implica, consecuentemente, que en el ámbito de lo estatal, lo político se convierte en determinante sobre lo económico-espacial, contrariamente a lo que ocurre en el bloque histórico, en donde tiene lugar la relación inversa. ${ }^{10}$ En este sentido, el Estado ampliado es la unidad de la sociedad política, como ámbito en donde se condensan las relaciones políticas de la sociedad y se concentra la coerción, y la sociedad civil, como ámbito del conjunto de las instituciones llamadas privadas y donde se concentra el consenso. La diferencia entre el concepto de Estado y el de Estado en un sentido restringido consiste en que mientras éste se circunscribe a la sociedad política y se refiere al ejercicio del aspecto coercitivo de la hegemonía, aquél comprende el ejercicio del conjunto del proceso hegemónico en torno al cual se articula la sociedad civil y sus instituciones, configurando y reconfigurando un espacio nacional. ${ }^{11}$

El Estado en sentido restringido también tiene un sentido restringido de su espacialidad, entendida como la forma de la organización en el espacio de su

cambio de una fase de desarrollo a otra (o de época histórica), la cual surge de la producción y la economía y se proyecta a la política, específicamente mediante un proceso de "catarsis" (la proyección de un nuevo "mito" social), así como a la ideología y la cultura, proceso que debe culminar con la formación de una nueva forma de Estado, en tanto que condensación de las relaciones políticas de la sociedad; véase Gramsci (1975) y Ordóñez (1996).

${ }^{10}$ La afirmación de Marx (1933, p. 14) que dice: "El conjunto de [las] relaciones de producción constituye la estructura económica de la sociedad, la base real, sobre la cual se eleva una superestructura jurídica y política y a la que corresponden formas determinadas de conciencia”, es interpretada por Gramsci como relación dialéctica, y no determinista en un solo sentido, entre estructura económica y superestructuras complejas, lo que lo hace romper con el determinismo económico de la Tercera Internacional.

${ }^{11}$ La distinción entre ambos conceptos está relacionada con la transformación en las formas históricas de dominación de las clases dominantes en el capitalismo que se verifican con posterioridad a la experiencia de la Comuna de París en 1871, transformación en la cual el consenso, como componente de la función hegemónica, pasa a adquirir una importancia cualitativamente superior en relación con la coerción, lo que hace necesario un cambio en la estrategia de la lucha de las clases y grupos subalternos consistente en el paso del asalto frontal al poder del Estado a la estrategia de hegemonía civil, lo que se corresponde en el arte militar con la transición de la guerra de movimientos a la guerra de posiciones; véase Gramsci (1975, pp. 763-764). 
entramado institucional, que es unitario, centralizado territorialmente, autocontenido e internamente diferenciado, lo que implica cambios en la configuración estatal territorial y en el papel de las fronteras y los límites geográficos en el orden internacional. Por su parte, el Estado ampliado tiene una espacialidad integral (o ampliada), entendida como la forma en que sus instituciones son desplegadas en el espacio para incidir sobre y mediar entre las relaciones sociales, además de influenciar su localización, lo que supone variaciones en la geografía de la intervención estatal para la reproducción económico-social dentro de una jurisdicción territorial dada (Brenner, 2004, p. 78). ${ }^{12}$

El Estado ampliado tiene, entonces, las siguientes funciones generales esenciales: 1) lograr el máximo desarrollo y expansión del grupo dirigente presentándolo como el máximo desarrollo y expansión de la sociedad y la nación, es decir, realizar los objetivos históricos del grupo dirigente presentándolo como la realización de los objetivos del conjunto de la sociedad y la nación; 2) adaptar a la sociedad civil a los requerimientos de la estructura económica, y, en particular, la extensión de la función hegemónica desde su origen dialéctico en la estructura económica hacia las superestructuras complejas nacionales (Gramsci, 1975, pp. 1253-1254). ${ }^{13}$

Si bien la problemática del papel del Estado en la reproducción y el desarrollo económicos no fue estudiada directamente por Gramsci, ya que su interés residía en el estudio de la hegemonía y el Estado burgueses con el objeto de trascenderlos históricamente, del concepto de Estado ampliado se pueden desprender los siguientes determinantes del accionar estatal en la reproducción y el desarrollo económico, en el entendido de que existe una inversión de la relación entre economía y política:

1) Está limitado por su contribución general a la solución del conflicto social y, en particular, del antagonismo que enfrenta a las clases y grupos

${ }^{12}$ Brenner (2004, pp. 78-79) se refiere a la espacialidad estatal en un sentido restringido y en uno integral, lo cual se corresponde con la distinción hecha por Gramsci en el concepto de Estado, entre su esfera ampliada y restringida. Cada escala de la organización y la acción estatal debe ser considerada en un sentido integral y en uno restringido. La espacialidad estatal integral incluye efectos socioespaciales indirectos de políticas aparentemente "aespaciales" en dos sentidos: efectos diferenciados de las políticas sobre localidades particulares y grupos sociales concretos en éstas, y el efecto espacial desigual de políticas nacionales, debido a su interacción con condiciones locales específicas. El sentido integral y el restringido interactúan recíprocamente dando como resultado formaciones históricas singulares de espacialidad estatal (Brenner, 2004, pp. 79).

${ }^{13}$ En ese sentido, el Estado y su accionar se ubican entre la estructura económica y la sociedad civil (Gramsci, 1975, pp. 1253-1254). 
hegemónicos con la clase subalterna fundamental en el marco del bloque histórico.

2) Cada época histórica tiene su propia forma de Estado (que incluye una forma espacial) ${ }^{14}$ y un accionar de éste para la reproducción y el desarrollo económico-espacial, dependiendo de la solución histórica al conflicto social, y, particularmente, al antagonismo esencial de clase, que se convierten en paradigmáticos de la época y determinan una cierta configuración no socialmente neutra y con una jerarquización de las escalas del espacio nacional. ${ }^{15}$

3) Los estados nacionales se relacionan en el marco supranacional de sistemas de hegemonía de estados, que consisten en la proyección internacional del bloque histórico nacional del país que se encuentra a la vanguardia en la solución de cada época al antagonismo y el conflicto social, y que cuenta con la suficiente capacidad de convocatoria internacional para convertirse en referente de los demás; ${ }^{16}$ estos sistemas de hegemonía implican un determinado patrón de desarrollo geográfico desigual, en el que las formas de independencia o soberanía nacionales implícitas o explícitas determinan as relaciones entre los estados, lo que es decisivo para la posición y las posibilidades de desarrollo de las potencias medianas y pequeñas (Gramsci, 1975, p. 1562).

4) La predominancia del accionar del Estado ampliado sobre el Estado en sentido restringido, y viceversa, depende de la capacidad hegemónica de las clases y grupos dirigentes nacionales, correspondiendo en general a una fuerte capacidad hegemónica (predominancia de la función de direc-

${ }^{14}$ Las formas espaciales del Estado se definen conforme al principio de territorialidad y se refieren a la organización en el espacio de su entramado institucional territorialmente centralizado, autocontenido y unitario, en el marco de un orden interestatal (Brenner, 2004, p. 78).

${ }^{15} \mathrm{En}$ el fordismo-keynesiansimo, el Estado fue un interventor centrado en un acuerdo de escala nacional, como inversionista productivo, en la creación de las condiciones generales de la acumulación y la generación de una demanda agregada, que posibilitaban el crecimiento económico fundamentalmente a partir del incremento de la demanda interna de los países, en una dinámica espacial de homogeneización de las regiones en torno a la escala nacional. Con esta forma de Estado (social-nacional) culmina la tradición epistemológica del desarrollo de las ciencias sociales centradas en el Estado (sociedades configuradas nacionalmente en la sociología, culturas articuladas territorialmente en la antropología o economías nacionales dinámicas en la ciencia económica), desarrollo epistemológico que oculta ideológicamente la creciente centralidad nacional del poder del Estado desde finales del siglo XIX (Brenner, 2004, pp. 38-39).

${ }^{16}$ Como jefe y guía de un sistema más o menos extendido de alianzas y acuerdos entre estados, en torno a los objetivos internacionales y nacionales que la potencia hegemónica se propone (Gramsci, 1975, pp. 1598). 
ción sobre la coerción) un accionar reducido del Estado en sentido restringido y un fuerte accionar del Estado ampliado, entendido básicamente en su parte de sociedad civil, y a una débil capacidad hegemónica (predominancia de la función de coerción sobre la de dirección), un accionar fuerte del Estado en sentido restringido (sociedad política), situación que puede ser una característica secular de un Estado determinado o asumir una forma coyuntural, de acuerdo con la relación de fuerzas político-sociales supranacionales y nacionales en un momento dado.

5) Correspondientemente, el Estado tiene una selectividad espacial, entendida como el proceso de supremacía y de articulación espacio-escala de las políticas estatales, por medio del cual éstas se diferencian a través del territorio, a fin de dirigirse a zonas geográficas o escalas particulares, lo que implica tanto la formulación de proyectos estatales espaciales, dirigidos a incidir sobre el propio entramado institucional estatal, como de estrategias estatales espaciales, dirigidas a incidir sobre la acumulación y reproducción del capital y las relaciones hegemónicas (Brenner, 2004, p. 90). ${ }^{17}$

6) Por último, el caso del fuerte accionar del Estado en sentido restringido supone una fuerte autonomía relativa de éste, que abre la posibilidad de la formación de intelectuales orgánicos-políticos "lúcidos" que encabecen una estrategia de desarrollo separadamente, en términos relativos, del "sentir" general de las clases dirigentes y desde el Estado, en una situación que implica la sustitución de la clase por el Estado.

A la síntesis de las vertientes de la teoría del Estado, básicamente desde lo político, llevada a cabo a partir de los desarrollos de Gramsci sobre el Estado ampliado, Marx habría agregado previamente (Juanes, 1982 pp.439-442) un elemento fundamental desde lo económico. Del desarrollo de los elementos de su teoría del Estado a partir de la teoría de la enajenación del individuo y la cosificación de las relaciones sociales -con su correlato en la teoría de la enajenación de la actividad productiva del individuo (el trabajo) y de su producto (la mercancía) -, se desprende que el Estado constituye la representación del ser social ante la imposibilidad del individuo (necesariamente social) de reafirmarse inmediata-

\footnotetext{
${ }^{17}$ Brenner (2004, p. 90) define los proyectos estatales espaciales como iniciativas para diferenciar la territorialidad del Estado en una geografía regulatoria funcionalmente coordinada, organizacionalmente coherente y dividida en partes, mientras que las estrategias estatales espaciales se refieren a estrategias para incidir en la geografía del desarrollo industrial, de la inversión en infraestructura y del antagonismo y la conflictividad social.
} 
mente como tal ser. Ello se deriva del desarrollo de la división social del trabajo en la forma histórica de la división de la sociedad en clases sociales -resultado de la aparición de la propiedad privada sobre los medios de producción-, que en el capitalismo alcanza su forma extrema, lo que se traduce en que la división social del trabajo y la ubicación del individuo en ella aparece ante él como un poder independiente y ajeno que lo domina. En tal situación, el individuo sólo es mediatamente social a través del mercado y la competencia en lo económico y mediante el Estado en lo político. ${ }^{18}$

A partir de esa concepción del Estado y de acuerdo con Juanes (1982), Marx plantea -complementándose con el desarrollo ya expuesto a partir de la noción gramsciana y su articulación con las recientes aportaciones espacialescalares- que un determinante adicional de la acción del Estado para la reproducción y el desarrollo económicos es garantizar la existencia de las condiciones generales de la acumulación de capital, que tienen que ver básicamente con dos elementos: a) el desarrollo de la infraestructura necesaria y común a todos los capitales individuales y b) el proceso de reproducción social de la fuerza de trabajo. En una perspectiva gramsciana-escalar, estos dos elementos tienen que ser considerados no sólo en la perspectiva del capitalismo como modo de producción, sino también en la de sus fases de desarrollo, esto es, como elementos cambiantes en cada fase, de acuerdo con sus características específicas y distintivas, y en la de su espacialidad, como se verá más adelante, en la nueva fase de desarrollo del capitalismo.

\section{Determinantes adicionales del accionar estatal en los países en desarrollo}

Para considerar la perspectiva específica y distintiva de los países en desarrollo en el marco de las fases es necesario incorporar al análisis las conclusiones que se desprenden de tres importantes aportaciones teóricas, replanteadas en términos de la doble dimensión histórica del capitalismo y de la perspectiva de las fases de desarrollo que se desprende de ella, a saber: a) la operación de la ley del valor a escala internacional, desarrollada por Shaikh (1990) a partir de los fundamentos elaborados por Marx; b) la teoría del desarrollo desigual y combinado, sistematizada por Trotsky (2000), y c) la perspectiva de la especificidad del atra-

\footnotetext{
${ }^{18}$ Marx plantea que si el Estado es la encarnación del ser social del individuo, el Estado nación es la encarnación de la identidad nacional territorial de los individuos, en donde los intereses de las clases dominantes se presentan como los intereses nacionales (Juanes, 1982, p. 441).
} 
so elaborada por Gerschenkron (1968). La primera de ellas, la operación de la ley del valor a escala internacional, implica una crítica a la dualidad ricardiana que tiende a considerar al intercambio interno (nacional) como determinado por el tiempo de trabajo necesario o "costos medios", mientras que el intercambio internacional estaría determinado por los costos comparativos. Tal dualidad adquiere una cierta coherencia conceptual cuando la teoría de la mercancía en Ricardo dejas de fundamentarse en la idea del valor como tiempo de trabajo necesario, para sustentarse en la del valor de cambio y los precios comparativos (como mera equiparación de costos entre las diversas mercancías), a lo que corresponde los costos comparativos internacionales. A esa teoría de la mercancía basada en el valor de cambio corresponden, entonces, una teoría cuantitativa del dinero y el postulado de que el comercio internacional basado en costos comparativos resulta benéfico para todos los países participantes, en la medida en que todos obtienen beneficios de la especialización internacional, derivados del ahorro en costos de producción internos.

Por el contrario, en Marx (1999) la ley del valor implica que cada mercancía tiene un valor individual determinado por el tiempo de trabajo socialmente necesario, que cuando se considera al conjunto de una rama de la producción se traduce en un valor social que incorpora a la ganancia media de dicha rama (en lugar de la ganancia individual) y cuando se considera al conjunto de las ramas de la producción, aquél se transforma en precio de producción, que incorpora a la ganancia social media, en torno al cual oscilan los precios de mercado bajo el efecto añadido de la oferta y la demanda. Este conjunto de valores y precios implican tanto procesos de extracción de plusvalor con la excepción del precio de mercado- como de apropiación-transferencia de valor entre capitales individuales y ramas productivas, de tal modo que en el tránsito del valor individual al valor social los capitales individuales con composición orgánica (capital constante (C) / capital variable (v)) mayor a la media de la rama se apropian de valor por transferencia de los capitales individuales con composición orgánica menor a la media de la rama. Al igual, en el tránsito del valor social al precio de producción, las ramas con composición orgánica por arriba de la composición orgánica social media se apropian de valor por transferencia de las ramas con composición orgánica por debajo de la media (Shaikh, 1990, pp. 195-216).

En el comercio entre países la competencia al nivel de ramas productivas tiende a formar ganancias medias internacionales por rama y valores internacionales que las incorporan (no intrarramas, como supone Shaikh, por que ello 
implicaría una libre movilidad global de capital y trabajo), desplazando de su formación a la ganancia media nacional, lo que implica igualmente procesos de apropiación-transferencia entre capitales/países, como se ejemplifica en el cuadro 1. Redimensionado en la perspectiva de las fases de desarrollo, el pasaje del fordismo-americanismo y la competencia multinacional al capitalismo del conocimiento y su dimensión espacial en la globalización, trae consigo el tránsito de valores internacionales multinacionales a valores globales al nivel de rama.

\section{Cuadro 1. Transferencia internacional del valor}

\begin{tabular}{|l|c|c|}
\hline & $\begin{array}{c}\text { Alta composición orgánica } \\
\text { de capital (c/v) } \\
\text { Intrarrama }\end{array}$ & $\begin{array}{c}\text { Baja composición orgánica } \\
\text { de capital (c/v) } \\
\text { Intrarrama }\end{array}$ \\
\hline Alta productividad & + & + \\
\hline $\begin{array}{l}\text { Baja productividad } \\
\text { (países en desarrollo) }\end{array}$ & - & - \\
\hline
\end{tabular}

Fuente: Shaikh (1990).

Los niveles de productividad relativamente bajos de los países en desarrollo tanto en ramas de alta composición orgánica de capital como de baja composición, implican la predominancia de procesos de transferencia de valor negativa, de lo que se desprende que, de suyo, el comercio internacional, lejos de beneficiar a todos los países participantes, como afirma Ricardo y la teoría neoclásica posterior hasta los años setenta del siglo xx, implica procesos de apropiación-transferencia de valor, que para los países en desarrollo, al predominar las trasferencias negativas, tienden a profundizar la brecha de desarrollo con los países avanzados. ${ }^{19}$ De la ley del desarrollo desigual y combinado, se sigue que a ella corresponde un determinado patrón de desarrollo geográfico desigual, correspondiente a la contradicción espacial entre las tendencias a la desterritorialización y la reterritorialización específica de cada fase de desarrollo. En esa perspectiva, los países en desarrollo combinan las condiciones, formas y desarrollos a escala más avanzados de la fase con las más atrasadas, lo que implica

\footnotetext{
${ }^{19}$ En el comercio internacional entre países en desarrollo y países avanzados tendería a prevalecer el principio de la ventaja absoluta, mientras que en el intercambio entre países de igual desarrollo sí tendería a prevalecer el principio de la ventaja comparativa (Shaikh, 1990).
} 
una compresión o compactación de los estadios y escalas "clásicos" del desarrollo y nuevas combinaciones y formas híbridas. Tal enfoque es completamente compatible con la caracterización de la especificidad del atraso que hace Gerschenkron (1968), compuesta de dos factores a los que es posible agregar un tercero, referente a la dimensión espacial, a saber: 1) los países avanzados se convierten en fuentes de asistencia técnica, medios de producción y fuerza de trabajo calificada para los países en desarrollo, además de que cuentan con industrias y actividades tecnológicamente más adelantadas a partir de las cuales éstos pueden emprender procesos de aprendizaje; 2) los países en desarrollo mismos ven acentuada la importancia para el desarrollo del carácter del Estado como representante de lo social-espacial -que puede conducir a una situación de sustitución de la clase por el Estado- y de todos los procesos parciales de racionalización social, lo que se expresa en una mayor relevancia de la banca de desarrollo, la centralización del capital en las ramas de medios de producción y de materias primas elaboradas, el incremento en el ritmo del desarrollo y su realización mediante saltos y discontinuidades (Gerschenkron, 1968, pp. 39-59), y 3 ) considerando ambas perspectivas, la combinación desigual y jerárquica de espacios y escalas mutuos, de acuerdo al patrón de desarrollo geográfico desigual y los procesos de desterritorialización/reterritorialización correspondientes, proceso en el cual cobra una importancia específica la selectividad estatal espacial y su incidencia sobre el desarrollo.

De lo anterior se desprenden determinantes específicos del accionar estatal en la reproducción y el desarrollo económicos para los países menos avanzados, que se agregan a los de orden general discutidos previamente, a saber: 1) acción contrarrestante del proceso de transferencia internacional de valor; 2) acción contrarrestante del desarrollo geográfico desigual y la promoción de la incorporación de las condiciones, formas y escalas más avanzadas de la fase y abandono de las más atrasadas; 3 ) aprovechamiento de las condiciones, formas y escalas híbridas y específicas; 4) potenciamiento de los procesos parciales de racionalización social, incluida la selectividad estatal espacial, y 5) potenciamiento del desarrollo en saltos y discontinuidades e incremento del ritmo de desarrollo. Una vez discutidos los determinantes generales de la acción estatal en la reproducción y el desarrollo económicos desde una perspectiva socioespacial y los específicos para los países en desarrollo, a continuación se abordarán los determinantes de la acción estatal correspondientes a la actual fase de desarrollo, buscando igualmente aproximarse a la especificidad de los dichos países en el marco de la crisis del neoliberalismo. 


\section{CAPITAlismo del CONOCIMIENTO Y REQUeRIMIENTOS DE LA ACCIÓN ESTATAL EN EL MARCO DE LA CRISIS DEL NEOLIBERALISMO}

\section{La nueva fase de desarrollo o capitalismo del conocimiento ${ }^{20}$}

Para abordar la problemática de los determinantes específicos de la acción estatal en la nueva fase de desarrollo, es necesario aproximarse previamente a los nuevos determinantes del desarrollo propios de esta fase, sobre la base de los determinantes generales previamente estudiados. La nueva fase de desarrollo del capitalismo surge como respuesta a la desaceleración de los incrementos de productividad que determinó el agotamiento de la fase fordista-keynesiana en los países avanzados hacia finales de los años sesenta del siglo Xx.

Una fase de desarrollo del capitalismo se da cuando una revolución tecnológica se traduce en una nueva base productiva y una nueva forma de producción, que traen consigo el surgimiento de nuevos productos, servicios y ramas de actividad, los cuales se convierten en los sectores que tienden a articular al resto de la actividad económica y a dinamizar su crecimiento. ${ }^{21}$ Sin embargo, este proceso puede no consumarse si las transformaciones de la economía no se acompañan de cambios en la forma de organización y en la solución al antagonismo y la conflictividad entre las clases y grupos sociales, así como en la ideología y la cultura, entendida ésta como modo de vida. Es decir, si no se constituye una nueva unidad orgánica entre economía, política, ideología y cultura -con su espacialidad específica-, los cambios que se originan en la economía (en particular en la forma de producción) y, por tanto, preceden a los demás, no pueden concretarse sin las transformaciones en esos otros ámbitos, que tienen sus propios condicionantes, abortando históricamente todo el proceso.

En la nueva fase de desarrollo, la solución a la desaceleración de los incrementos en la productividad se ha encontrado en una creciente incorporación de conocimiento a la producción social, a partir de lo cual se ha generado una

\footnotetext{
${ }^{20}$ Este apartado sintetiza lo desarrollado ampliamente en Ordóñez (2004; 2009a) y en Ordóñez y Bouchaín (2011).

${ }^{21}$ Schumpeter (1939, p. 84) y los neoschumpetrianos (Dosi, 1998, p. 9) distinguen la existencia de distintos sectores tecnológicamente originados o revolucionados por una revolución tecnológica, que dinamizan el crecimiento en cada ciclo industrial, cuya duración es de 50 a 60 años (aun cuando la evidencia empírica mostraría la tendencia a su reducción). En ellos parece estar implícita la noción de que tales sectores tienden a articular el crecimiento de los demás ("induced growth sectors"), concepción que Fanjzylber (1983, p. 341) hace explícita en su noción de patrón industrial.
} 
nueva y específica dinámica económica con características propias, que la diferencian de estadios precedentes. En consecuencia, el conocimiento tiende a convertirse en la principal fuerza productiva del crecimiento económico, lo que se traduce en un incremento notable como contenido de la producción social a partir de los años ochenta (Ordóñez, 2009a, p. 383), proceso que se expresa, por ejemplo, en el incremento sustancial del número de patentes concedidas $\mathrm{y}$, consecuentemente, aplicadas en la economía de EU de 1983 en delante (de alrededor de sesenta mil en ese año a alrededor de ciento setenta mil en 2001) (Powell y Snellman, 2004), ${ }^{22}$ así como en la tendencia al incremento del número de artículos científicos citados en las patentes (en las concedidas por la United States Patent and Trademark Office, el promedio aumenta de 0.5 a 3 de 1987 a 1998, proceso que también se observa en otros países importantes) (Ordóñez y Bouchaín, 2011, p. 31). ${ }^{23}$

Espacialmente el capitalismo del conocimiento conlleva a que no sea más el capital el que tiende a ser moldeado en la territorialmente integrada geografía del espacio estatal, como en el fordismo-keynesiano, sino éste el que tiende a ser moldeado en la territorialmente integrada geografía global del capital (Brenner, 2004, p. 16), o sea, el proceso de globalización. La nueva fase de desarrollo surge de una nueva articulación entre el sector científico-educativo y el conjunto de la producción social, en la que aquél se convierte en una condición inmediata de la producción, por lo que la producción, circulación y acumulación del conocimiento tiende a incidir e involucrar a todos los ámbitos de la reproducción económica y social, lo que trasciende las instituciones científico-educativas y las empresas e incluye nuevas instituciones económico-sociales de facto, formales e informales.

La nueva articulación entre el sector científico-educativo y la producción social es posible gracias a la revolución tecnológica de la informática y las telecomunicaciones, cuyo despliegue se traduce en una nueva base tecnológica productiva que tiende a articularse con el toyotismo, en tanto que nueva forma

${ }^{22}$ La United States Patent and Trademark Office y la Japan Paten Office son las entidades con más solicitudes de patentes mundialmente, alrededor de 340 mil cada una en e 2002, muy por encima de la European Patent Office, con alrededor de 110 mil (OCDE, 2004, p. 7). La aplicación de la ciencia y el conocimiento en la producción social no es novedosa en el capitalismo, al constituir uno de sus aspectos civilizadores, pero esta tendencia secular da un salto de calidad con la revolución tecnológica de la informática y las comunicaciones (Foray, 2000, p. 28).

${ }^{23}$ Son los casos, por ejemplo, de Canadá ( 0.5 a 2.5), Australia ( 0.5 a 2.5), Reino Unido $(0.5$ a 2), Suecia (0.5 a 1.5), Finlandia (0.5 a 1.5), Francia (0.5 a 1), Alemania (0.5 a 0.5$)$ y Japón (0.5 a 0.5) (OCDE, 2001, p. 22). 
de dirección y organización de los procesos de trabajo, que persigue, a diferencia del fordismo, la incorporación de la calidad en los procesos productivos y en el producto social y, por esa vía, conocimiento, particularmente el conocimiento tácito de los operarios. ${ }^{24}$ Por consiguiente, tiene lugar la formación de un ciclo del conocimiento (producción, circulación y acumulación) que incluye al sector científico-educativo y a la producción, circulación y el consumo sociales, en el cual el gran desafío histórico es la valorización del conocimiento (creación de nuevo valor a partir del conocimiento), lo que supone una dilatación y autonomización de las actividades de concepción y diseño del producto en relación con las actividades de manufactura, lo cual, a su vez, permite una diferenciación de la composición de los costos de producción entre ambas actividades, en los siguientes términos: a) la fase de concepción y diseño es intensiva en capital variable $^{25}$ y poco intensiva en capital constante, consistiendo el primero en trabajo complejo intelectual altamente calificado, y b) la fase de manufactura tiende a una mayor proporción de capital constante en relación con el variable (al igual que la composición del capital en su conjunto), ${ }^{26}$ aun cuando la proporción específica de ambos depende del tipo particular de actividad y su ubicación dentro de la cadena de valor.

La composición de costos particular de la concepción y diseño conlleva que su proceso de reproducción se realice de un modo específico, debido a que: a) supone altos costos de producción derivados de un proceso altamente intensivo de creación de conocimiento, por parte del trabajo vivo intelectual altamente calificado, y su objetivación en la primera unidad del producto, y b) sus costos de reproducción son mínimos, puesto que consisten únicamente en la reproducción de la materialidad o en la copia sucesiva de la primera unidad del producto, en la cual el conocimiento ha sido ya objetivado. ${ }^{27}$

\footnotetext{
${ }^{24}$ El toyotismo persigue objetivos contrarios al fordismo, puesto que se trata de producir pequeñas series de productos diferenciados y variados, incorporando las propuestas de mejora del proceso de trabajo y del producto por parte del operario (Coriat, 1991, pp. 41-51).

${ }^{25}$ De acuerdo con Marx (1899, p. 159) el capital variable es el capital invertido en la compra de fuerza de trabajo, mientras el capital constante es el destinado a la compra de edificios, maquinaria, equipo, materias primas y auxiliares.

${ }^{26}$ Se trata de la tendencia al aumento de la composición orgánica del capital (si c = capital constante y v = capital variable, $\mathrm{c} / \mathrm{v}$ expresa la relación entre la composición técnica del capital cociente de los montos físicos de capital constante sobre los de capital variable- y su composición de valor-cociente de los mismos componentes expresados en valores-), que se traduce en una tendencia a la disminución de la tasa de ganancia. Véase Marx (1959, p. 213).

${ }^{27}$ Arthur (1994, p. 3) cita el ejemplo del primer disco de Windows en ser producido, con un costo de USD 50 millones, en relación con el segundo y las copias subsecuentes, con un costo de USD 3.
} 
Lo anterior implica que la composición de costos particular de los productos intensivos en conocimiento, o del producto parcial derivado de la fase de concepción y diseño, constituye una composición de capital específica que contrarresta el aumento de la composición orgánica del capital -al ser intensiva en capital variable y poco intensiva en capital constante-, por lo que la valorización del conocimiento constituye una nueva contratendencia a la caída de la tasa de ganancia, derivada del aumento de la composición orgánica del capital (Ordóñez, 2004; 2009a), como puede observarse, por ejemplo, en el comportamiento de la tasa de ganancia de las corporaciones no financieras de EU con posterioridad a 1980, mostrado en Ordóñez y Bouchaín (20011, p. 34). ${ }^{28}$

El ciclo implica, entonces, una nueva e íntima relación entre el conocimiento y la producción social, en la cual aquél es simultáneamente un insumo y un resultado de la producción, bajo la forma de capacidades productivas y procesos de innovación, respectivamente (Amin y Cohendet, 2004, p. 11). Pero esto no puede tener lugar si no se verifica un proceso generalizado de movilización social orientada a la innovación y el aprendizaje, que implica que los objetivos de inclusión y equidad sociales dejen de tener un mero contenido ético-político, como en el fordismo-keynesianismo, y adquieran un nuevo carácter estratégico para el desarrollo de los países, en el marco de una división global del trabajo y una competencia internacional centradas en el conocimiento y la diferenciación productiva. $^{29}$

En el nivel macroeconómico, el despliegue de la revolución informática y de las comunicaciones trae consigo la integración de un nuevo complejo tecnológico-productivo, constituido por el conjunto de actividades industriales y de servicios articuladas por las tecnologías básicas del circuito integrado, el software y la digitalización, al cual se denominará sector electrónico-informático y de las telecomunicaciones (SEIT) ${ }^{30}$, cuya composición se muestra en el cuadro 2. El SEIT se convierte en el nuevo núcleo articulador y dinamizador de la produc-

${ }^{28}$ La composición de capital específica contrarresta el incremento en la composición orgánica del capital y, en consecuencia, la tendencia a la disminución de la tasa de ganancia; véase Marx $(1959$, p. 213). En el conjunto, la ley de la tendencia a la disminución de la tasa de ganancia sigue operando, pero con una nueva contratendencia que tendrá efectos directos sobre la división del trabajo entre las empresas en el contexto de las redes productivas.

${ }^{29} \mathrm{La}$ incorporación del conocimiento en la producción constituye el fundamento de la diferenciación productiva en la competencia internacional, la cual requiere, por tanto, de la inclusión social y la incorporación del conocimiento inmerso en las culturas originarias específicas de los países.

${ }^{30}$ En trabajos anteriores se había utilizado la denominación de sector electrónico-informático, pero ahora se añade el término "y de las telecomunicaciones", en virtud de la importancia creciente 
146 ECONOMÍA: TEORÍA Y PRÁCTICA • Nueva Época, número 41, julio-diciembre 2014

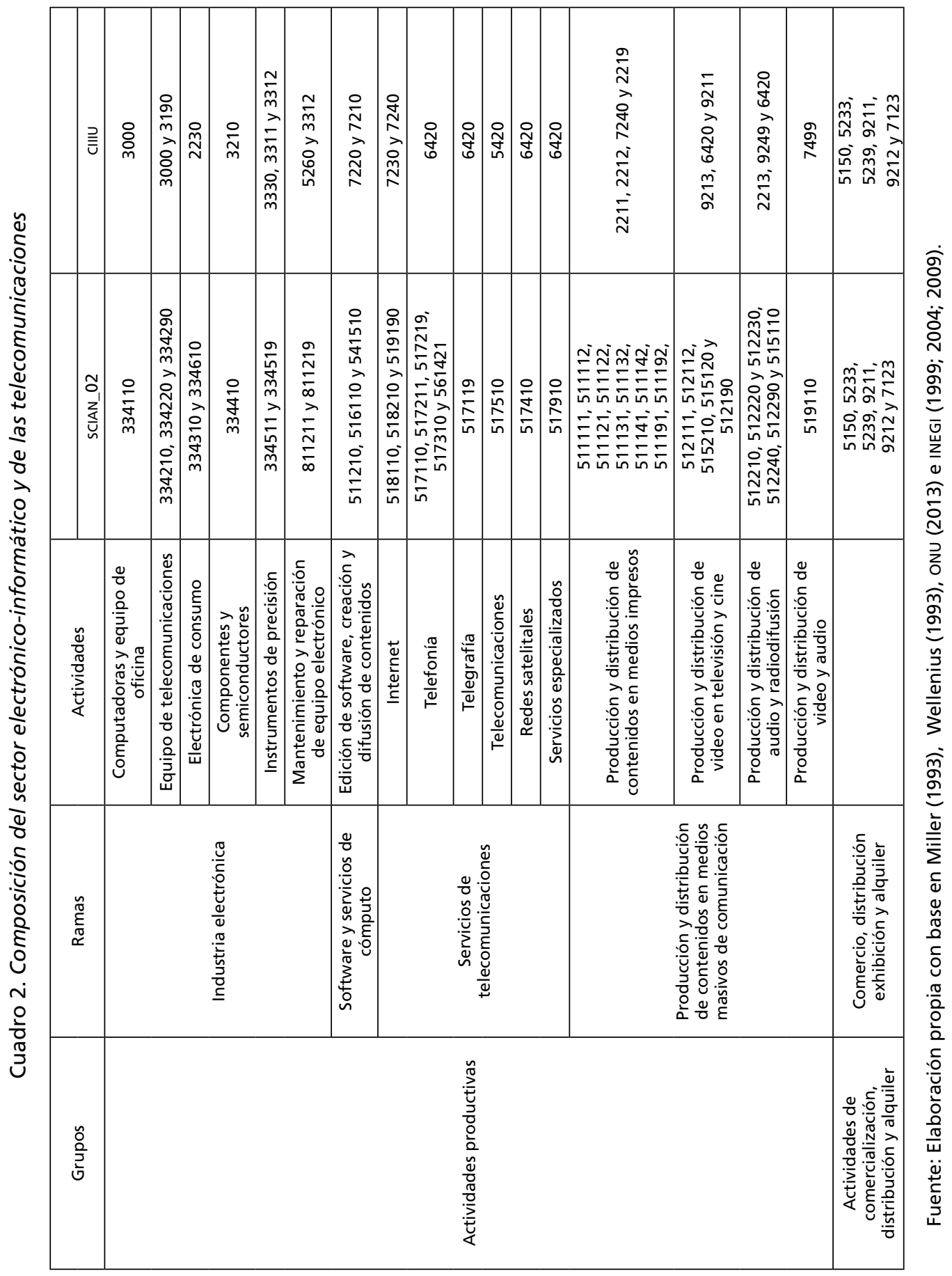


ción, el crecimiento y el comercio mundiales, en substitución del complejo automotriz-metalmecánico-petroquímico, propio de la fase de desarrollo fordista-keynesiana, lo que se traduce en un nuevo dinamismo económico o ciclo industrial con características propias, derivadas de los siguientes aspectos específicos que lo diferencian del antiguo complejo:

a) La valorización del conocimiento se traduce en una ganancia creciente por escala de producción asociada a una modificación del patrón de competencia, en la medida en que el productor que logra establecer su estándar tecnológico en un sector productivo determinado obtiene una ganancia extraordinaria y una posición de monopolio "natural" hasta que se produce una innovación fundamental en el sector (De Long y Summers, 2000, p. 49). ${ }^{31}$

b) Establece una relación mucho más directa e integrada con las restantes actividades productivas, tanto en el nivel de las tecnologías de proceso (productivas, organizacionales, laborales, informativas, de mercadeo) como de producto (incorporación del microprocesador a los más diversos medios de producción, consumo duradero e infraestructura física, operación de puentes, canales, ductos, etcétera) (Dabat y Ordóñez, 2001, p. 26). ${ }^{32}$

c) Integra "hacia delante", suministrando insumos a prácticamente todas la industrias y servicios, ${ }^{33}$ y no "hacia atrás", demandando insumos, como el antiguo complejo industrial. ${ }^{34}$

de esta actividad en el marco de la convergencia tecnológica y de servicios actual, y de su importante peso específico creciente en el sector.

${ }^{31}$ En este sentido, el SEIT conforma una economía schumpeteriana, en la cual la innovación es el medio para obtener ganancias extraordinarias y una posición de monopolio "natural" por parte de las empresas, y el equilibro competitivo es un estado improbable, a diferencia de la fase fordistakeynesiana, que es smithiana, en la que la competencia es entre productos "rivales" y "excluyentes", y el equilibrio competitivo un estado probable (Long y Summers, 2000, p. 33).

${ }^{32}$ Un aspecto central de la nueva tecnología no generalmente bien comprendido es la refuncionalización e integración a un nuevo nivel del conjunto de la infraestructura física existente, tanto de comunicaciones y eléctrica, como de transporte (operación electrónica de trenes, puentes, canales, ductos, etcétera) (Dabat y Ordóñez, 2009, p. 26).

${ }^{33}$ En el caso de EU destacan actividades como servicios telefónicos y telegráficos, transmisión por radio y televisión, servicios de salud, industria cinematográfica, servicios de negocios, oficinas de holding e inversión, servicios legales, comercio al mayoreo, aseguradoras, instrumentos y productos relacionados, etcétera.

${ }^{34}$ La industria del automóvil integraba "hacia atrás" a las industrias de maquinaria, acero, química, del petróleo y eléctrica. 
d) En el ciclo económico generado, la oferta va dinamizando a la demanda y no al contrario, como en el ciclo económico de la fase fordistakeynesiana.

e) Si en el ciclo económico anterior era necesaria la regulación de la demanda agregada para mantener la oferta en crecimiento (con el consecuente déficit fiscal), en el actual se requeriría la regulación de la oferta a precios decrecientes, puesto que ésta sería la condición para que la oferta dinamice a la demanda, lo que haría compatible el crecimiento con un superávit fiscal, como ocurrió en el ciclo expansivo de la economía estadounidense de los noventa, a partir de los fundamentos del nuevo ciclo industrial y sin perturbaciones "exógenas", o durante 2000-2010 con el ciclo expansivo de los países escandinavos, los cuales, como se verá más adelante, son los más avanzados en la conformación de una nueva forma histórica de Estado. ${ }^{35}$ La dinámica del ciclo económico basado en el ciclo industrial del SEIT, comparada con la del ciclo keynesiano, se muestra en el cuadro 3.

Lo anterior se traduce en un comportamiento diferente del ciclo económico en los siguientes términos: 1) la fase expansiva del ciclo sería más prolongada y el nivel de incremento de las tasas de crecimiento y aumento de la productividad se elevaría, debido al papel dinámico de la oferta (a precios decrecientes) sobre la demanda, a la mayor integración del SEIT con el resto de las actividades económicas y a la tasa más acelerada de innovación propia de la nueva base tecnológica; ${ }^{36}$ y 2) la fase contractiva del ciclo sería menos duradera y rece-

${ }^{35}$ Esta problemática, aunque crucial, permanece prácticamente inexplorada en la literatura. La expansión estadounidense tuvo lugar sin la aplicación de la política keynesiana de estímulo a la demanda agregada y en su consecución fue fundamental el estímulo inicial del Estado a industrias clave, como la del software, con efectos multiplicadores en la inversión y la infraestructura (Borrus y Strowky, 1997, p. 2). La crisis que cierra el ciclo sobrevino, en términos estructurales, por una sobreacumulación de capital manifestada por una sobreinversión de las empresas en equipo electrónico-informático y de las telecomunicaciones. Para evidencia empírica al respecto, véase Colecchia y Shreyer (2001) y Dabat y Ordóñez (2009). Según cifras oficiales del Fondo Monetario Internacional (IMF, 2013), en los países escandinavos, por su parte, el ciclo expansivo de la primera década del siglo XXI se acompañó de superávit fiscales (Noruega, 13\% del PIB; Finlandia, 3\%; Dinamarca, $2 \%$, y Suecia, $1 \%$, en promedio, respectivamente).

${ }^{36}$ La fase expansiva de la economía estadounidense en los noventa tuvo una duración de casi diez años (segundo trimestre de 1991 al segundo trimestre de 2000), una tasa de crecimiento media de $4.1 \%$ en $1995-2000$ (contra $4.2 \%$ en 1959-1973) y una tasa media de incremento de la productividad de $3.2 \%$ en $1995-2000$ (contra $2.9 \%$ en 1959-1973). El incremento acelerado de la produc- 
Cuadro 3. Comparativo del ciclo keynesiano con el ciclo del SETI

Dinámica del ciclo keysiano: la oferta sigue a la demanda

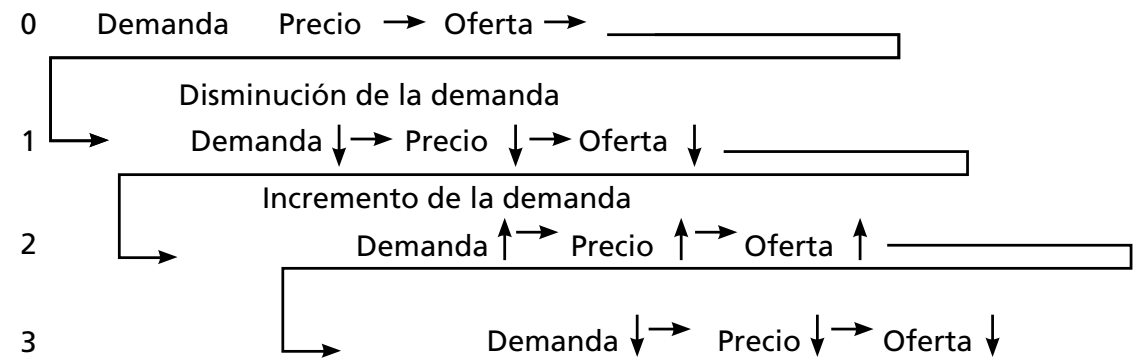

Dinámica del ciclo industrial basado en el SETI: la oferta impulsa a la demanda

0 Oferta $\rightarrow$ Precio $\rightarrow$ Demanda

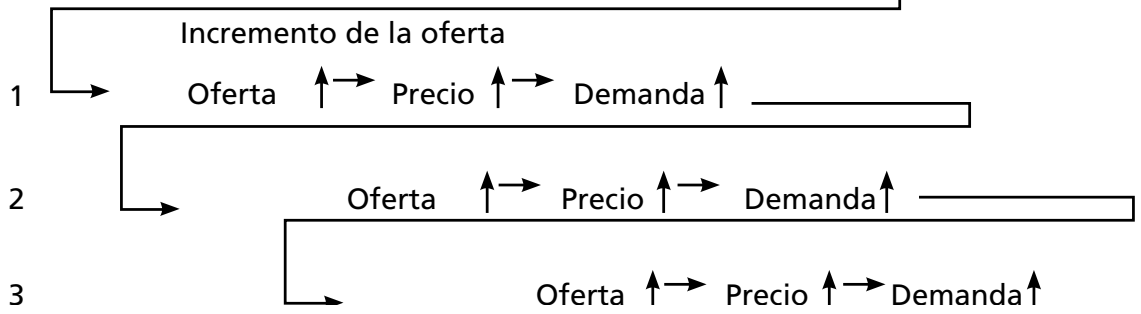

Fuente: Elaboración propia con base en Lewis (1997).

siva, puesto que la organización de la producción en redes globales se traduce en un coeficiente menor de inventarios respecto de los pedidos y las ventas, con lo que la dinámica tradicional de una mayor contracción de la producción que de la demanda (las ventas efectivas), debida a los inventarios, se vería contrarrestada, siendo más rápida y fácil la recuperación de la producción (USDC, 2000, p. 16; De Long y Summers, 2000, p. 32). ${ }^{37}$ La globalización, en tanto que dimensión espacial del capitalismo del conocimiento, implica la necesidad de un redimensionamiento de la escala geográfica nacional a partir de un nuevo dinamismo de

tividad se tradujo en niveles más bajos de desempleo e inflación y en incrementos importantes del salario real (Baily, 2000, p. 3).

${ }^{37}$ En la contracción económica de 2001-2002 sólo hubo tres trimestres recesivos $\left(2000_{3}, 2001_{1}\right.$ y $\left.2001_{3}\right)$ y tuvo una duración de diez trimestres $\left(2000_{3}-2002_{4}\right)$ (US-BEA, s.f), aunque en ello incidió la situación de incertidumbre que se creó con posterioridad al 11 de septiembre de 2001, derivada de los atentados terroristas, la crisis de la aviación comercial, la guerra de Irak y el aumento en los precios del petróleo. 
las escalas regional y local, y una nueva relación de "abajo-arriba" con lo nacional, que le permita a ésta desempeñar un papel activo fundamental en el proceso de rejerarquización de las escalas geográficas, a partir del cual tenga lugar una rearticulación, mediada por la escala nacional, de lo supranacional con lo regional-local (Brenner, 2004, p. 205; Fernández y Alfaro, 2011, p. 86).

Sobre esos fundamentos, el SEIT dinamiza la fase expansiva de los noventa, determina la crisis mundial de 2001 y 2002 y encabeza la recuperación posterior, a partir de un proceso de reestructuración tecnológico-productiva con consecuencias en su despliegue espacial mundial y su división interindustrial e internacional del trabajo (Dabat y Ordóñez, 2009, p. 392). Por su parte, la reciente crisis financiera-productiva global de 2007-2009, al estar centrada en el sector inmobiliario y los valores respaldados en hipotecas, aspecto desarrollado ampliamente en otros lugares (Ordóñez, 2009b, pp. 60-69), tuvo repercusiones directas sobre el SEIT mundial derivadas de dos procesos íntimamente relacionados: 1) los efectos recesivos sobre el conjunto de la actividad económica, a la cual este sector provee de insumos productivos industriales y de servicios en una relación de articulación "hacia delante", resultado de la disminución de la demanda mundial, y 2) la escasez y posterior virtual congelamiento del crédito mundial, con repercusiones adicionales sobre una contracción generalizada de la inversión en el sector y de la inversión en equipo electrónico-informático en el conjunto de la economía (Ordóñez, 2009b, p. 69).

El seIT está jugando, nuevamente, un papel articulador y dinamizador en la recuperación (observable claramente a partir del tercer trimestre de 2009), como lo muestra la gráfica 1 en lo referente a la composición de las exportaciones mundiales por grupos de productos, debido a que la promoción del desarrollo por parte de este sector constituyó un componente fundamental de los paquetes de estímulos económicos de los gobiernos para impulsar la recuperación $^{38}$ y en la mayor parte de ellos la inversión en la industria de servicios de telecomunicaciones pasó a desempeñar un rol propulsor de la recuperación de la inversión en su conjunto, bajo la óptica de que una nueva inversión en infraestructura que promueva la recuperación, además del componente físico tradicional, debe incluir, muy importantemente, un nuevo componente digital, constituido

\footnotetext{
${ }^{38}$ Los países del G-20 invirtieron cerca de USD 2 billones, de los cuales USD 100000 millones corresponden a actividades relacionadas con el SEIT. Como porcentaje del PIB, Corea, Japón y EU han hecho las mayores inversiones ( $11 \%, 0.7 \%$ y $0.3 \%$, respectivamente), y como porcentaje del paquete de estímulos, Corea, Francia y Japón han sido los países principales (24\%, 17\% y 12\%, respectivamente) (ITIF, 2009, p. 19).
} 


\section{Gráfica 1. Exportaciones mundiales de mercancías y productos electrónicos, químicos, textiles, automotrices, petroleros y eléctricos (años seleccionados, miles de millones de dólares corrientes)}

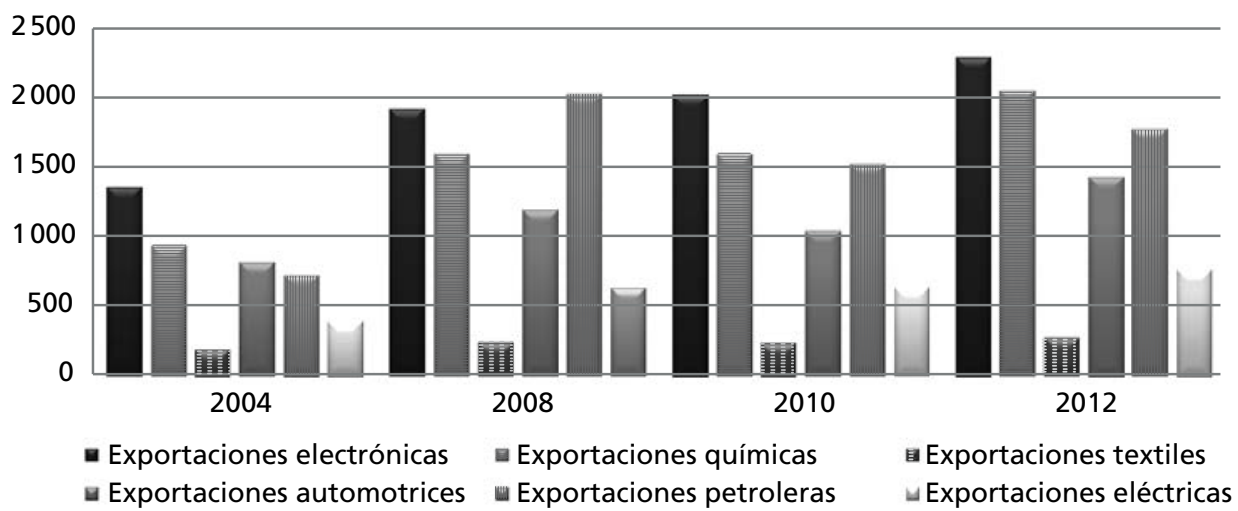

Fuente: United Nations (s.f).

por redes de banda ancha alámbricas e inalámbricas que contribuyan a alcanzar el objetivo de un acceso universal a Internet en los países más desarrollados. En el momento actual, la recuperación mundial tiende a desacelerarse y a enfrentar importantes límites derivados de la incapacidad de los gobiernos de los países desarrollados de romper con los fundamentos del neoliberalismo, en favor de una vía de desarrollo alternativa, inclusiva y fundamentada en la participación social en los nuevos procesos de conocimiento, lo que se traduce en que las causas de fondo que dieron origen a la crisis no hayan sido enfrentadas más que muy parcialmente mediante tímidas reformas, como la del sistema sanitario y el sistema financiero en $\mathrm{EU}^{39}$, quedando problemas de fondo sin resolver, como los si-

\footnotetext{
${ }^{39}$ Las reformas al sistema sanitario implican la extensión del seguro médico a aproximadamente treinta millones de personas para completar una cobertura casi universal, subsidios a personas de ingresos bajos y medios para acceder a la seguridad social privada, una regulación más estricta de las compañías de seguros (prohibición de denegar seguridad por "condiciones prexistentes", por ejemplo), además de economías que llevarían a la reducción del déficit federal. Por su parte, la reforma financiera incluye los siguientes aspectos esenciales: 1) extiende la regulación de los bancos y los mercados públicos a otras instituciones (private equity firms, hedge funds, etcétera) e instrumentos financieros, como los derivados que circulan en mercados ocultos (los bancos están obligados a segregar o desprenderse de sus divisiones de negocios con derivados); 2) crea un consejo de reguladores federales para el monitoreo y la detección de riesgos en el sistema financiero, que incluye atributos para contener y desmantelar compañías en problemas; 3 ) prohíbe a los bancos, cuyos depósitos están asegurados por la autoridad federal, a traficar con su propio capital, y 4) crea una nueva agencia de protección del consumidor ante prácticas y productos financieros (New York Times, 2010).
} 
guientes: 1) el agotamiento de una configuración del intercambio global en que la condición de EU como gran deudor internacional se complementa con la de gran exportador manufacturero mundial de China, lo que plantea, en el caso de esta última, la necesidad de reorientar relativamente su crecimiento hacia el mercado interno y el consumo privado, y, en el caso del primero, de reducir la dependencia de su crecimiento del consumo interno a crédito y basarlo predominantemente en la inversión productiva; 2) la falta de reforma a la intermediación del nuevo capital financiero internacional, que se traduce en la persistencia de los efectos de la crisis financiera global en la volatilidad de los mercados financieros, que está afectando particularmente a Europa, y en la formación de burbujas financieras en torno al crédito que ha financiado la reciente expansión del Sur global y alrededor del sector inmobiliario en China; 3) la falta de reforma de las instituciones económicas y políticas del sistema de hegemonía de estados encabezado por EU, que se expresa en el continuado papel marginal de los países en desarrollo en la gobernanza de la economía mundial, no obstante la importancia económica creciente del Sur global, convertido en eje dinámico de la acumulación mundial, lo que le confiere un papel crucial en la recuperación actual.

\section{Crisis del neoliberalismo y requerimientos de la acción estatal en la reproducción y el desarrollo económicos: visión desde los países en desarrollo}

La reciente crisis financiero-productiva global y sus secuelas actuales muestran que de la nueva fase de desarrollo del capitalismo, cuya dimensión espacial es la globalización, sólo ha emergido su base tecnológica-productiva, sin que ésta haya podido encontrar proyección aún en una trama socioespacial e institucional correspondiente a sus requerimientos de desarrollo políticos, ideológicos, culturales y espaciales, y, por tanto, en una nueva forma histórica de Estado. En cambio, el despliegue de esa nueva base tecnológico-productiva ha tenido lugar sobre todo bajo la envoltura de la vía de desarrollo neoliberal y su espacialidad de nuevo regionalismo global, que consiste en una racionalización de la trama socioespacial e institucional heredada de la fase fordista-keynesiana, pero liberada de los anteriores compromisos corporativos y distributivos con las clases y grupos subalternos, así como de la centralidad espacial de la escala nacional.

La predominancia mundial de esa vía de desarrollo, basada en el dogma del libre juego de las fuerzas del mercado y el desmantelamiento y la fragmentación del espacio nacional, posibilitó el surgimiento de un nuevo capital financie- 
ro, el cual actuó inicialmente como una enorme palanca para el despegue mundial de la nueva base tecnológica-productiva, proceso que desemboca en la crisis mundial de 2001-2002, centrada en el índice NASADAQ. En un segundo momento, el desarrollo de la informatización y la autonomización del nuevo capital financiero, su crecimiento extremo, la búsqueda de rentabilidad inmediata y sus prácticas parasitarias, se han magnificado, convirtiéndolo en una enorme traba al ulterior despliegue de la nueva base tecnológica-productiva, cuya dinámica ha quedado supeditada a los requerimientos de la valorización financiera y a una espacialidad "glocalizadora" (Ordóñez, 2009b, p. 61).

Lo anterior se ha traducido en un incremento de la desigualdad social al interior de los países y una ampliación de la brecha de desarrollo entre ellos en un sentido tanto "horizontal" como "vertical" de sus escalas geográficas; todo ello contrario a los requerimientos socioespaciales de la base tecnológico-productiva del nuevo capitalismo, en términos de la formación de un ciclo interno de conocimiento, con involucramiento e inclusión sociales, además de la articulación por parte de los países de la diferenciación y ubicación multiescala competitiva de sus territorios en la división global del trabajo, lo que constituye el fundamento de la actual crisis del neoliberalismo (Ordóñez, 2009b, p. 61). De los requerimientos de la nueva base tecnológico-productiva se desprenden los siguientes nuevos determinantes del accionar estatal en la reproducción y el desarrollo económicos propios de esta nueva fase de desarrollo, los cuales, en consecuencia, constituyen al mismo tiempo lineamientos de la acción estatal para la superación de la crisis del neoliberalismo:

1) Intermediación de la integración en el mercado mundial y la globalización en relación con la reproducción y acumulación interna, y articulación nacional de la diferenciación y ubicación multiescala del territorio en la división global del trabajo.

2) Articulación del sector científico-educativo con el conjunto de la producción social e inclusión social en el ciclo interno de conocimiento.

3) Desarrollo de una infraestructura informática y de las telecomunicaciones, con acceso y uso generalizado.

4) Necesidad de la reproducción cognitiva, y, por tanto, física de la fuerza de trabajo, es decir, el desarrollo del trabajo complejo. ${ }^{40}$

${ }^{40} \mathrm{O}$ el llamado "capital humano", esto es, el conjunto de conocimientos e ideas innovadoras desarrolladas en cualquier momento por las personas en las empresas, universidades y el gobierno, 
5) Promoción del surgimiento y desarrollo de sectores productivos claves dentro del SEIT, con efectos multiplicadores sobre la inversión y la producción. ${ }^{41}$

6) Provisión de una oferta creciente de productos del SEIT a precios decrecientes que aseguren un ciclo de crecimiento en el que la oferta dinamice a la demanda, complementada con medidas que eviten perpetuar el monopolio "natural" y den aliento a la innovación tecnológica. ${ }^{42}$

7) Proyectos y estrategias estatales espaciales de reconfiguración multiescala de la organización institucional del Estado y de su despliegue espacial para incidir en la reproducción económica-social y espacial, en términos de una rejerarquización de las escalas en torno a lo nacional, reconfigurado con un nuevo dinamismo de las escalas subnacionales y nueva relación "de abajo-arriba".

Desde la perspectiva de los países en desarrollo, a lo anterior se agregan los siguientes determinantes específicos de la acción estatal, de acuerdo con la condición particular de estos países en la nueva fase de desarrollo:

1) Fuerte accionar del Estado en sentido restringido (sociedad política) y su predominancia sobre el accionar del Estado ampliado (sociedad civil), ante la débil capacidad hegemónica de las clases y grupos dominantes para dirigir un proyecto histórico en torno al desarrollo del conocimiento social y la diferenciación y ubicación multiescala competitiva en una división global del trabajo articulada en torno a la escala nacional.

2) Acción contrarrestante de la transferencia internacional de valor, que en el marco de la globalización asume la forma del ascenso en las redes

\footnotetext{
lo que supone la necesidad de inversión en educación, capacitación, salud, etcétera.

${ }^{41}$ Un sector es clave en tres sentidos: 1) tiene una contribución mayor al progreso tecnológico que es central para el crecimiento de largo plazo, 2) cuenta con una tasa de retorno para los sujetos de la producción mayor que cualquier otra actividad económica y 3) tiene efectos externos, como la aceleración de la innovación tecnológica, que benefician ampliamente al resto de la economía (Borrus y Stowsky, 1997, p. 9). Por ejemplo, las industrias estadounidenses de la computación y del software surgieron y se desarrollaron gracias al subsidio del Estado al desarrollo tecnológico y la protección de la competencia externa (Flamm, 1993, p. 163).

${ }^{42}$ Esto es, medidas que eviten que los productores con un monopolio "natural" en una generación de productos utilicen esa posición para retardar la innovación tecnológica o para asegurarse una posición sumamente ventajosa en la competencia de la siguiente generación de productos (De Long y Summers, 2000, p. 49).
} 
productivas globales y su articulación con redes productivas internas, así como el desarrollo de propiedad intelectual propia, mediante procesos de aprendizaje e innovación.

3) Acción contrarrestante del desarrollo geográfico desigual y la promoción de la incorporación de las condiciones, formas y escalas más avanzadas de la nueva fase, como son las tecnologías de punta y emergentes, las ciudades inteligentes, etcétera, y el abandono de las condiciones y escalas más atrasadas.

4) aprovechamiento de las condiciones, formas y escalas híbridas y específicas, que en las condiciones actuales se puede traducir en el alargamiento del ciclo de vida de productos maduros orientados a nichos específicos para generar rentas internacionales de aprendizaje (Dabat, Rivera y Sztulwark, 2007, p. 13) o, en términos escalares, el desarrollo de regiones que integran procesos geoeconómicos de países desarrollados y en desarrollo más allá de los límites nacionales.

5) Potenciamiento de los procesos parciales de racionalización social, en términos de una estrategia nacional multiescala de desarrollo, como una nueva banca de desarrollo y la centralización del capital en industrias ligadas a la renta del suelo y la infraestructura física e informática y de las telecomunicaciones, así como de la selectividad estatal espacial, mediante la promoción de regiones o localidades con ventajas competitivas específicas en la división global del trabajo

6) Potenciamiento del desarrollo a saltos y discontinuidades e incremento de su ritmo con base en pasos de innovación acelerados y en el aprendizaje y la innovación social.

Seguir algunos de estos lineamientos de la acción estatal es lo que ha permitido a los países escandinavos emprender una vía de desarrollo alternativa al neoliberalismo, que incluye el desarrollo de elementos de una nueva trama socioespacial e institucional articulada por un nuevo compromiso hegemónico en torno al "liberalismo solidario" y el Estado innovador multiescala (Jessop, 2008, p. 37; Brenner, 2004, p. 125), acorde con los requerimientos de la nueva base tecnológico-productiva, así como llevar a cabo un proceso de ascenso industrial, la formación de un ciclo industrial interno articulado por las nuevas actividades dinámicas del SEIT y ubicarse a la vanguardia en la formación de un ciclo interno de conocimiento, no obstante verse fuertemente condicionados en la actualidad por su estrecha vinculación productiva y comercial con la Unión 
Europea y su actual crisis. Pero el proceso más llamativo ha sido el ascenso de la macrorregión del Este asiático, particularmente China, que tiende a articularse desigualmente con la emergencia del Sur global, con base en un accionar estatal que igualmente sigue algunos de los lineamientos expuestos, en una combinación del desarrollo de la nueva base tecnológico-productiva con procesos de acumulación extensiva, la producción mercantil simple y el florecimiento de una enorme infraestructura física y energética. Es, por último, el caso de algunos países de América del Sur, como Argentina y Brasil, que en ese proceso han emprendido la búsqueda de vías de desarrollo alternativas al neoliberalismo fundadas en un nuevo accionar estatal.

\section{Conclusión}

Desde el punto de vista de las clases dominantes progresistas mundiales, la salida a la crisis del neoliberalismo estaría en el postulado neoinstitucionalista (particularmente de D. North), sobre la necesidad del tránsito a un régimen "abierto" de derechos de propiedad, el cual requiere de la plena competencia tanto económica como política, lo que implicaría la emergencia de un nuevo "hábito de pensamiento" en las coaliciones dominantes -por miedo a la rebelión de otras élites-, mediante el cual aquéllas vean más conveniente la apertura de los derechos de propiedad que continuar con el estado de exclusión vigente -convirtiendo sus antiguos privilegios en derechos impersonales-, en una nueva situación en que el desarrollo de la competencia impida la subsiguiente manipulación del sistema económico por el sistema político para la obtención de rentas que aseguren el orden político, lo que supone un desarrollo de la sociedad civil y un papel necesariamente más reducido del Estado en el proceso. La plena competencia económica y política se encuentra espacialmente en línea de continuidad con la visión que busca promover las políticas de tercera generación de la industrialización regional ${ }^{43}$, en términos de la potenciación de la competitividad sistémica de las

${ }^{43}$ Las políticas de primera generación tienen lugar en el marco del fordismo-keyenesianismo y del Estado social, el cual, a partir de una "nacionalización de las escalas" (Brenner, 2004, p. 114), formula políticas que promueven los polos de desarrollo y los complejos industriales, con el objetivo de atenuar las desigualdades regionales. Las políticas de segunda generación tienen lugar en el marco de la emergencia y despliegue del capitalismo del conocimiento, bajo el desarrollo neoliberal y las políticas correspondientes de fragmentación y desmantelamiento del espacio nacional en los años ochenta y noventa, cuando, sobre la base del modelo de la especialización flexible, se promueven los agrupamientos industriales predominantemente formados por pequeñas y medianas 
regiones, orientada al desarrollo de las vinculaciones productivas y la formación de redes de empresas, y entre éstas y las instituciones locales de apoyo, así como de las articulaciones multiescala verticales entre instancias y programas locales, nacionales y supranacionales, con el fin de aprovechar los beneficios de la inversión y el comercio extrarregionales (Helmsing, 1999, citado por Palacios, 2008, p. 12), con un Estado que ya no funge como guía, ejecutor y principal fuente de financiamiento, sino como coordinador de los esfuerzos de cooperación y colaboración entre los diversos agentes que intervienen en el proceso de industrialización regional (Palacios, 2008, p. 13).

Esa visión de futuro, y particularmente la necesidad de un nuevo "habito de pensamiento" de las coaliciones dominantes, implica, desde el punto de vista del marxismo gramsciano, un proceso de revolución pasiva,${ }^{44}$ en el cual las clases y grupos dominantes que pretenden crear nuevas condiciones para la transformación radical de las fuerzas productivas -dando necesariamente un paso hacia la socialización de la producción y el desarrollo de la división social del trabajo- requieren desarrollar e integrar, como propios, elementos histórico-político-culturales ajenos e, incluso, contrarios a ellos y pertenecientes a las clases y grupos subalternos, pero necesarios para incorporar el desarrollo tecnológico y preservar su hegemonía sobre el conjunto de la sociedad en el marco de una inédita fase de desarrollo que implica un nuevo proyecto histórico. En esa misma perspectiva, la potenciación de la competitividad sistémica de las regiones y las articulaciones multiescala "verticales" entre instancias y programas locales, nacionales y supranacionales, siguen implicando un proceso de desmantelamiento y fragmentación del espacio nacional y de diferenciación y ubicación multiescala competitiva del territorio nacional en la globalización a partir de condicionantes "glocales" y no de premisas nacionales. En ese escenario posneoliberal promovido por intelectuales "lúcidos" de las clases dominantes mundialmente, la "vuelta", en la literatura, y el paso adelante, en la acción, hacia una nueva forma histórica del Estado y de su accionar en la reproducción y el desarrollo eco-

empresas, teniendo como eje la cooperación entre ellas, las asociaciones industriales, los sindicatos y los gobiernos locales (Palacios, 2008, p. 12).

${ }^{44} \mathrm{O}$ revolución-restauración, proceso que posibilita que sean únicamente estas clases y grupos dominantes los que logren desarrollar todas sus posibilidades de acción, para no dejarse superar históricamente por las clases subalternas (Gramsci, 1975, p. 1768). Por consiguiente, a través de la revolución pasiva, las clases y grupos dominantes, ya sea directamente o por medio del Estado -que es lo más frecuente-, asumen requerimientos históricos del desarrollo social y elementos ajenos e incluso contrarios, pertenecientes a las clases y grupos subalternos, dentro de un proyecto histórico propio. 
nómicos es primordial, con una intensa participación activa de la sociedad civil y de las clases y grupos subalternos, orientados a la innovación y el aprendizaje social multiescala, particularmente en los países en desarrollo.

\section{REFERENCIAS BIBLIOGRÁFICAS}

Amin, Ash, y Cohendet, Patrick (2004), Architectures of Knowledge, London, Oxford University Press.

Arthur, Brian (1994), Increasing Returns and the Path Dependence in the Economy, Michigan, The University of Michigan Press.

Baily, Martin Neil (2000), Macroeconomic Implications of the New Economy, US, BRIE/ University of California Berkeley.

Block, Fred, y Evans, Peter (2007), "El Estado y la economía”, en Peter Evans, Instituciones y desarrollo en la era de la globalización neoliberal. Bogotá, ILSA, pp. 307338

Borrus, Michael, y Stowsky, Jay (1997), “Technology Policy and Economic Growth”, working paper 97, BRIE/University of California Berkeley.

Brenner, Neil (2004), New State Spaces: Urban Governance and the Rescaling of Statehood, London, Oxford University Press.

Chibber, Vivek (2003), Locked in place: state building and late industrialization in India, Princeton, Princeton University Press.

Colecchia, Alessandra, y Schreyer, Paul (2001), The Impact of Information Communications Technology on Output Growth, sTI Working Paper 2001/7.

Coriat, Benjamín (1991), Pensar al revés: Trabajo y organización de la empresa japone$s a$, México, Siglo xxi Editores.

Dabat, Alejandro; Rivera, Miguel Ángel, y Sztulwark, Sebastián (2007), "Rentas económicas en el marco de la globalización: desarrollo y aprendizaje. Implicaciones para América Latina", Problemas del Desarrollo, 38 (151), octubre-diciembre, pp. 13-36.

Dabat, Alejandro, y Ordóñez, Sergio (2001), Revolución informática. Nuevo ciclo industrial y división internacional del trabajo: marco general para el estudio de la incursión internacional de México, México, CRIM/IIEc.

- (2009), Revolución informática, nuevo ciclo industrial e industria electrónica en México, México, IIEc/Unam/Casa Juan Pablos.

Dosi, Giovanni (1998), "Opportunities, incentives and the collective patterns of technological change", The Economic Journal, 107 (444), pp. 1530-1547. 
Fanjzylber, Fernando (1983), La industrialización trunca en América Latina, México, DF, Centro de Economía Trasnacional.

Fernández, Víctor Ramiro, y Alfaro, María Belén (2011), “Ideas y políticas del desarrollo regional bajo variedades de capitalismo: contribuciones desde la periferia", en Revista Paranaense de Desenvolvimento, 0 (120), pp. 57-99.

Flamm, Kenneth (1993), "Measurement of DRAm Prices: Technology and Market Structure”, en Murray F. Foss, Marilyn E. Manser y Allan H. Young (eds.), Price Measurements and Their Uses, Chicago, University of Chicago Press, pp. 157-206.

Foray, Dominique (2000), Economics of knowledge, London, The MIт Press.

Gerschenkron, Alexander (1968), El atraso económico en su perspectiva histórica, Barcelona, Ariel.

Gramsci, Antonio (1975), Quaderni del carcere (1932-1939), Torino, Einaudi-Istituto Gramsci.

Hilferding, Rudolf (1963), El capital financiero, Madrid, Tecnos.

IMF (2013), Nordic Regional Report. 2013 Cluster Consultation, Washington, DC, International Monetary Fund [PDF]. Consultado el 13 de enero de 2014, en: http:// www.imf.org/external/pubs/ft/scr/2013/cr13275.pdf.

INEGI (1999), Censos Económicos, México, Instituto Nacional de Estadística y Geografía e Informática.

— (2004), Censos Económicos, México, Instituto Nacional de Estadística y Geografía e Informática.

— (2009), Censos Económicos, México, Instituto Nacional de Estadística y Geografía e Informática.

ITIF (2009), The atlantic century. Benchmarking EU \& US Innovation and competitiveness, Washington, DC, Information Technology \& Innovation Foundation [pdf]. Consultado el 15 de enero de 2014, en: http://www.itif.org/files/2009-atlanticcentury.pdf.

Jessop, Robert (2008), El futuro del Estado capitalista, España, La Catarata.

Juanes, Jorge (1982), Marx o la crítica de la economía política como fundamento, Puebla, Universidad Autónoma de Puebla.

Lenin, Vladimir (1977), El imperialismo, fase superior del capitalismo, Moscú Progreso.

Lewis, Ted G. (1997), The Friction-Free Economy: Marketing Strategies for a Wired World, USA, Harperbusiness.

Long, James Bradford de, Summers, Lawrence Henry (2000), The "New Economy": Background, Historical Perspective, Questions, and Speculations, Us, BRIE/University of California Berkeley. 
Marx, Karl (1933), Contribución a la crítica de la economía política, Madrid, Librería Verruga.

- (1959), El capital. Crítica de la economía política, tomo III, 2a . ed. México, DF, FCE.

- (1999), El capital. Crítica de la economía política, tomo I, 3ª ed. México, DF, FCE.

Miller, Arnold (1993), "Building a Modern Electronics Industry”, en B. Wellenius, A. Miller y C. J. Dahlman (eds.), Developing the Electronics Industry, Washington, DC, The World Bank, pp. 15-28.

New York Times (2010), "Editorial - Financial Reform”, New York Times [en línea], 21 de mayo. Consultado el 23 de septiembre de 2010, en: http://www.nytimes. com/2010/05/22/opinion/22sat1.html?module=Search\&mabReward=relbias $\% 3$ $\mathrm{Ar} \% 2 \mathrm{C} \% 7 \mathrm{~B} \% 222 \% 22 \% 3 \mathrm{~A} \% 22 \mathrm{RI} \% 3 \mathrm{~A} 18 \% 22 \% 7 \mathrm{D} \& \_\mathrm{r}=0$.

North, Douglass (1990), Institutions, Institutional Change and Economic Performance, Cambridge, Cambridge University Press.

North, Douglas; Wallis, John Joseph, y Weingast, Barry (2009), Violence and social orders a conceptual framework for interpreting recorded human history, Cambridge, Cambridge University Press.

OCDE (2001), Measuring the ICT Sector, París, Organización para la Cooperación y el Desarrollo Económicos.

- (2004), Patents and innovation: Trends and policy challenges, París, Organización para la Cooperación y el Desarrollo Económicos.

Offe, Claus (1975), "The theory of the capitalist state and the problem of policy formulation”, en L. N. Lindberg, R. Alford, C. Couch y C. Offe (eds.), Stress and Contradiction in Modern Capitalism, London, Lexington Books, pp. 125-144.

ONU (2013), "Clasificación Industrial Internacional Uniforme de todas las actividades económicas, Rev. 3.", en Organización de Naciones Unidas. Consultado el 8 de febrero de 2013 en: http://unstats.un.org/unsd/cr/registry/regcst.asp? $\mathrm{Cl}=17 \&$ $\mathrm{Top}=2 \& \operatorname{Lg}=3$.

Ordóñez, Sergio (1996), “Cambio histórico mundial contemporáneo y pensamiento social: reforma del capitalismo y la revancha de Gramsci”, Iztapalapa, (0) 40, julio-diciembre, pp. 207-230.

- (2004), "Nueva fase de desarrollo y capitalismo del conocimiento: elementos teóricos", Comercio Exterior, 54 (1), enero, pp. 4-17.

(2009a), "El capitalismo del conocimiento. La nueva división internacional del trabajo y México", en Alejandro Dabat y Jesús Rodríguez (coords.), Globaliza- 
ción y conocimiento. El nuevo entorno del desarrollo económico de México, México, IIEc/CRIM/FE/UNAM, pp. 383-416.

(2009b), "La crisis global actual y el sector electrónico-informático", Problemas del Desarrollo, 40 (158), julio-septiembre, pp. 55-90.

- (2010), "New phase of development and knowledge capitalism: Gramsci's historical revenge?", International Gramsci Journal, 1 (2), abril, pp. 51-66.

Ordóñez, Sergio, y Bouchain, Rafael (2011), Capitalismo del conocimiento e industria de servicios de telecomunicaciones en México, México, IIEc-UnAm.

Palacios, Juan José (2008), Alianzas público-privadas y escalamiento industrial. El caso complejo de la alta tecnología de Jalisco, México, CEPAL - Series y Perspectivas 98, México, DF, Naciones Unidas.

Pérez, Carlota (2004), Revoluciones tecnológicas y capital financiero: La dinámica de las burbujas financieras y las épocas de bonanza, México, Siglo XXI.

Powell, Walter, y Snellman, Kaisa (2004), “The Knowledge Economy”, Annual Review of Sociology, 30, pp. 199-220.

Rivera, Miguel Ángel (2010), "Estado, atraso y desarrollo tardío. Una revisión histórica", en Alejandro Dabat (coord.), Estado y desarrollo, México, IIEc-Unam, pp. 65-98.

Shaikh, Anwar (1990), Valor, acumulación y crisis: ensayos de economía política, Bogotá, Tercer Mundo Editores.

Schumpeter, Joseph Alois (1939), Business Cycles: A Theoretical, Historical and Statistical Analisys of the Capitalist Process, New York, McGraw Hill.

Smith, Neil (1990), Uneven Development, 2a . ed., Cambridge, MA, Blackwell.

Trotsky, León (2000) La teoría de la revolución permanente, 2a. ed., Riobamba, CEIP/ Instituto del Pensamiento Socialista.

United Nations (s.f.), "International Trade Statistics Yearbook", en International Merchandise Trade Statistics. Consultado el 19 de mayo de 2014, en: http://comtrade. un.org $/ \mathrm{pb} /$.

US-BEA (s.f,) "GDP and the National Income and Product Account (NIPA) Historical Tables", en National Economic Accounts. Consultado el 7 de septiembre de 2004, en: http://www.bea.gov/national/index.htm\#gdp.

USDC (2000), The Emerging Digital Economy, New York, us Department of Commerce. Wellenius, Bjorn (1993), "Electronics and the Developing Economies: Introduction and Overview”, en en B. Wellenius, A. Miller y C. J. Dahlman (eds.), Developing the Electronics Industry, Washington, DC, The World Bank, pp. 4-24. 